\title{
Variaciones anatómicas en las raíces aéreas cortas de Oenocarpus bataua (Arecaceae)
}

Anatomical variations in the aerial roots of Oenocarpus bataua (Arecaceae)

\author{
Lorena Isabel Guevara Orozco ${ }^{1,2}$
}

\begin{abstract}
Resumen
Se describe la anatomía de las raíces aéreas cortas de Oenocarpus bataua que surgen desde la base del tallo hasta aproximadamente $80 \mathrm{~cm}$ por encima del nivel del suelo, comparando esta estructura entre especímenes a diferentes distancias de sus ápices y entre las raíces de primer y segundo orden. Las muestras fueron colectadas en Zamora Chinchipe (Ecuador). Se obtuvieron secciones transversales, longitudinales y macerados utilizando técnicas clásicas. Las raíces estudiadas no contienen tejido meristemático en el ápice. Las principales variaciones entre individuos son la presencia de elementos traqueales medulares aislados y endodermis profundamente lobulada en las raíces de primer orden más gruesas. Otras diferencias se encontraron en la exodermis y la corteza externa entre individuos, en términos de ausencia, presencia o variaciones en el número de capas celulares y engrosamiento de paredes, mientras que la estructura de la corteza interna se observó más constante. A distintos niveles desde el ápice, las raíces de primer orden muestran esclerificación centrífuga del tejido fundamental que rodea al tejido vascular. Las raíces de segundo orden tienen una anatomía más simple y menos variable.
\end{abstract}

Palabras clave: Arecoideae, estructura vegetativa, histología, palma.

\begin{abstract}
The anatomy of aerial short roots of Oenocarpus bataua that arise from the stem base up to approximately 80 $\mathrm{cm}$ from above ground level is described, comparing this structure between individuals at different distances from the apex and between primary and secondary roots. Samples were collected in Zamora Chinchipe (Ecuador). Transverse, longitudinal sections and macerates were made using classic techniques. The studied roots lacked apical meristematic tissue. Principal variations between individuals are the presence of medullar isolated tracheary elements and deep lobulated endodermis in thicker primary roots. Another differences between individuals are found in the exodermis and outer cortex in terms of absence, presence or variation on the number of cell layers and wall thickening, while the structure of the inner cortex showed more constancy. At different levels from the apex, primary roots show centrifugal sclerification of the fundamental tissue bordering the vascular tissue. Secondary roots have a simpler and less variable anatomy.
\end{abstract}

Key words: Arecoideae, vegetative structure, histology, palm.

\section{Introducción}

En algunas palmas es frecuente observar, por encima de la base del tallo, conjuntos densos de raíces aéreas cortas que no alcanzan al suelo. Estas fueron referidas por Mahabale \& Udwadia (1959) como raíces aéreas agrupadas. Varios autores hacen referencia a éstas como una agregación de raíces en una protuberancia o cojín basal del tallo y mencionan el término 'root boss' (Tomlinson 1961; Lewis 2002;
Dransfield et al. 2008). Tomlinson et al. (2011) indicaron como característico en algunas especies de Chamaedorea Willd., la presencia de raíces que aparecen de manera distal en el tallo y no contactan el suelo y en Thrinax L.f. ex Sw., grupos apretados de raíces superficiales en 'root boss'. Por su parte, Lewis (2002) consideró que para los miembros de la subtribu Oncospermatinae, la presencia de estas raíces superficiales es un carácter algo variable, posiblemente dependiente

\footnotetext{
${ }^{1}$ Investigadora Prometeo, Universidad Técnica Particular de Loja, Departamento de Ciencias Naturales, San Cayetano Alto s/n, C.P. 1101608, Loja, Ecuador.

${ }^{2}$ Autora para la correspondencia: loisag@gmail.com
} 
de las condiciones de crecimiento. La generación de raíces de crecimiento limitado por encima de la base del tallo de algunas palmas, la zona de proliferación de las mismas y su patrón de regeneración, son aspectos de vital importancia para el establecimiento exitoso luego del transplante de palmas ornamentales, debido a las raíces laterales que se desarrollan de las primarias que han sido cortadas (Hodel et al. 2005; Pittenger et al. 2005; Hodel 2009; Tomlinson et al. 2011).

Oenocarpus bataua Mart. es una palma de tallo solitario, que pertenece a la tribu Euterpeae de la subfamilia Arecoideae (Dransfield et al. 2008), crece de manera abundante en bosques bajos del norte de Suramérica y en laderas andinas hasta los $1000 \mathrm{msnm}$ (Henderson et al. 1995); no obstante, ha sido reportada a mayores altitudes (Borchsenius \& Moraes 2006). En observaciones sobre individuos de $O$. bataua de poblaciones dispersas en localidades de la Provincia de Zamora-Chinchipe, Ecuador, se encontró que dichos individuos frecuentemente desarrollan un ligero engrosamiento desde la base del tallo hasta un poco más arriba, de donde surgen raíces aéreas de crecimiento limitado (cortas), de las que a su vez se desarrollan raíces laterales a diferentes distancias del ápice.

La anatomía radical en especies dentro de las subfamilias de palmas, ha sido estudiada por algunos autores (Mahabale \& Udwadia 1959; Tomlinson 1961; Seubert 1996, 1998a,b; Tomlinson et al. 2011), quienes han descrito raíces subterráneas de individuos adultos y en algunos casos raíces aéreas tipo zanco. En estos trabajos se evidencia la complejidad de la anatomía radical en la familia. El arreglo de los tejidos radicales en palmas es muy variable dentro de una misma especie, por lo que su utilidad taxonómica a nivel específico debe ser tomada con cautela (Tomlinson et al. 2011). Por otra parte, este tipo de estudio se ha utilizado para caracterizar taxones artificiales a través de fragmentos de palmas fosilizados que corresponden a bases de tallos con el conjunto de raíces basales, lo cual ha servido en algunos casos para relacionarlas con especies actuales (Tidwell et al. 1972; Biondi \& Filigheddu 1990; Dutta et al. 2011). Recientemente, el estudio de las variaciones en el arreglo de los tejidos del meristema apical de la raíz, se ha empleado para interpretar las relaciones entre los principales clados de las angiospermas en un contexto evolutivo (Heimsch \& Seago 2008; Seago \& Fernando 2013).

Los estudios sobre la anatomía de las raíces aéreas en palmas son escasos, al igual que la información sobre las variaciones estructurales dentro de una misma especie. En este trabajo se caracteriza la estructura interna de las raíces aéreas cortas de primer y segundo orden de Oenocarpus bataua, identificando las variaciones entre las mismas, entre individuos y a distintas distancias del ápice, con la finalidad contribuir al esclarecimiento de la estructura radical dentro de la tribu Euterpeae de las Arecaceae desde la perspectiva de variabilidad intraespecífica.

\section{Materiales y Métodos}

Del conjunto denso de raíces aéreas en la base del tallo de cuatro individuos de $O$. batana creciendo en la Provincia de Zamora Chinchipe en Ecuador (Tab. 1), se extrajeron raíces de primer orden maduras y juveniles, a una altura de 20 a

Tabla 1 - Especímenes estudiados de Oenocarpus bataua Mart. con datos de las colecciones.

Table 1 - Oenocarpus bataua Mart. specimens studied with collection data.

\begin{tabular}{llc}
\hline Datos de colección & $\begin{array}{l}\text { Colectores y número } \\
\text { de colección }\end{array}$ & $\begin{array}{l}\text { Diámetro promedio } \\
\text { raíces muestreadas (cm) }\end{array}$ \\
\hline $\begin{array}{l}\text { Parroquia Zurmi, Cantón Nangaritza, Provincia Zamora } \\
\text { Chinchipe. } 880 \text { msnm (17 760625 E, 9544886 S) }\end{array}$ & F. Tinitana et al. 1272 & 0,65 \\
$\begin{array}{l}\text { Parroquia Zurmi, Cantón Nangaritza, Provincia Zamora } \\
\text { Chinchipe } 880 \text { msnm (17 760625 E, 9544886 S) }\end{array}$ & F. Tinitana et al. 1273 & 1 \\
$\begin{array}{l}\text { Vía antigua Loja-Zamora, Cantón Zamora, Provincia Zamora } \\
\text { Chinchipe. } 1200 \text { msnm (17 721423 E, 9554718 S) }\end{array}$ & F. Tinitana et al. 1281 & 0,45 \\
$\begin{array}{l}\text { Tunantza, Cantón Zamora, Provincia Zamora Chinchipe } 960 \\
\text { msnm (17 730912 E, 9552016 S) }\end{array}$ & N. Cumbicus et al. 2085 & 0,95 \\
\hline
\end{tabular}


$80 \mathrm{~cm}$ desde el nivel del suelo. El material de comprobación se encuentra depositado en el Herbario de la Universidad Técnica Particular de Loja (HUTPL), en la ciudad de Loja, Ecuador. De estas raíces se tomaron trozos de aproximadamente 4-6 cm de longitud incluyendo el ápice y se fijaron en $\mathrm{FAA}_{70}$ (formaldehido, ácido acético glacial y etanol 70\%) según Johansen (1940). Se realizaron secciones transversales y longitudinales radiales a mano alzada de 3 raíces por individuo, desde el ápice hasta un poco más arriba de donde se localizó la zona de formación de raíces laterales, a 5,$0 ; 2,5 ; 1,0 ; 0,1$ y $0,02 \mathrm{~cm}$ con respecto al ápice. Adicionalmente, se realizaron secciones de raíces de segundo orden, a 1,$5 ; 1,0 ; 0,5 ; 0,3 ; 0,2$ y $0,1 \mathrm{~cm}$ del ápice. Las secciones se aclararon utilizando blanqueador comercial diluido (Tomlinson et al. 2011), fueron teñidas con una solución al $0,01 \%$ de azul de toluidina acuosa (Johansen 1940), montadas en portaobjetos con glicerina-agua 1:1 (v/v), cubiertas con cubreobjetos y selladas con esmalte para uñas transparente, a fin de obtener láminas semipermantentes. Se realizaron macerados del cilindro vascular para estudiar la morfología de los elementos xilemáticos, utilizando una mezcla de peróxido de hidrógeno (10\%) y ácido acético (puro) 1:1 (v/v), durante 48 horas (Franklin 1945).

Las láminas se analizaron utilizando un microscopio óptico y a través de una cámara adaptada a este, se obtuvieron micrografías de la estructura anatómica. Las secciones se describieron siguiendo la terminología de Tomlinson et al. (2011).

\section{Resultados}

Morfología de las raíces aéreas cortas de O. bataua

Raíces de primer orden creciendo de manera descendente, entre 5 y $15 \mathrm{~cm}$ de longitud, con raíces de segundo orden desde aproximadamente $4 \mathrm{~cm}$ del ápice, no alcanzan el suelo, son de color pardo rojizo y sus ápices poseen una cofia de apariencia seca color pardo más oscuro (Fig. 1).

Anatomía de las raíces aéreas cortas de Oenocarpus bataua Mart.

Región meristemática ausente tanto en las raíces de primer como de segundo orden, en su lugar, los tejidos de esta zona se aprecian esclerificados y con contenido celular color pardo. Raíces de segundo orden con estructura más constante que las de primer orden a distintos niveles desde el ápice. Se presenta la descripción de las variaciones en la estructura interna de raíces maduras de primer orden a distintos niveles desde el ápice radical, comparándolas con las juveniles (Figs. 2-4) y con las de segundo orden (Fig. 5). Algunas de estas variaciones se resumen en la Tabla 2.
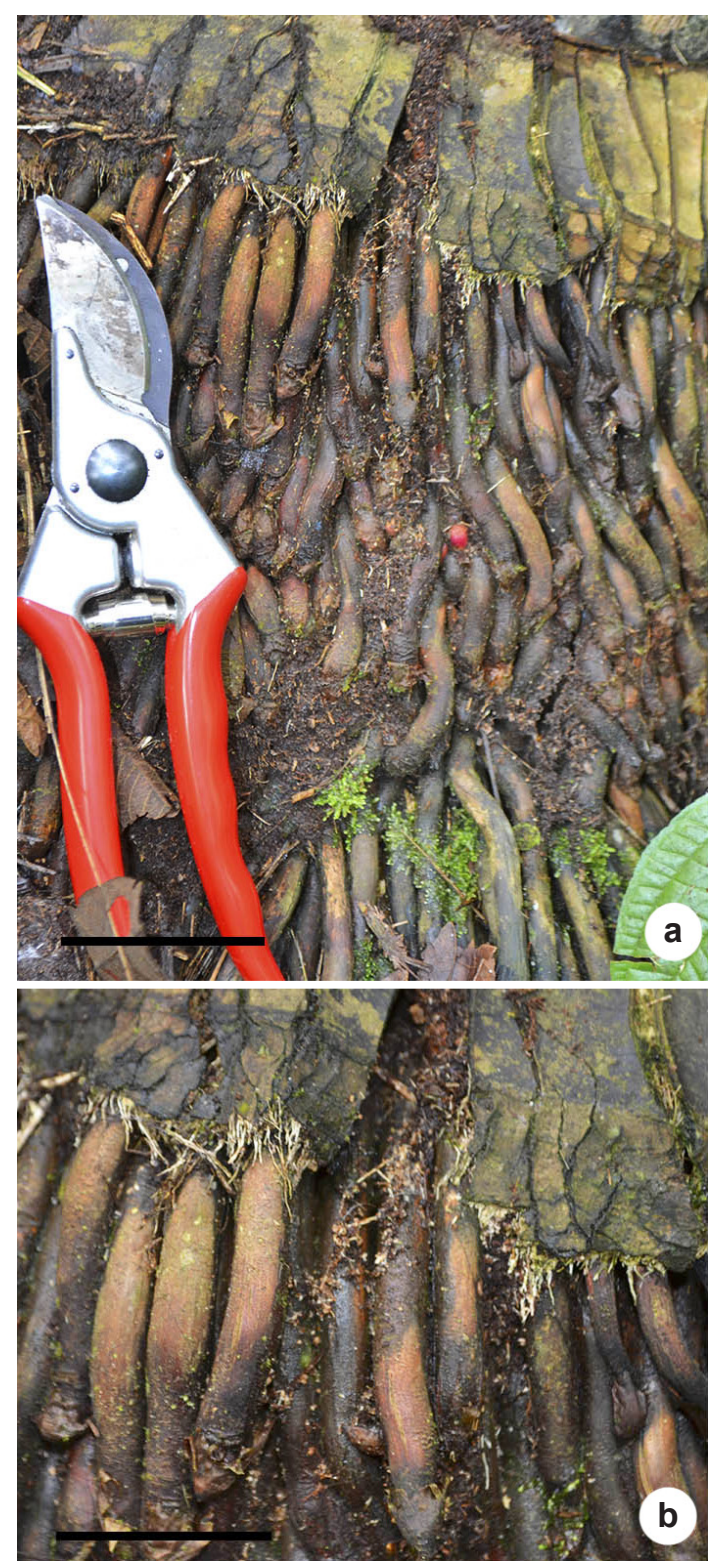

Figura 1 - a. raíces de primer orden en la base del tallo de un individuo de Oenocarpus bataua Mart.; b. detalle de la imagen anterior. Barras: $a=5 \mathrm{~cm} ; \mathrm{b}=3 \mathrm{~cm}$.

Figure 1 - a. primary roots in the stem base of an individual of Oenocarpus bataua Mart.; b. detail of the previous image. Bars: $\mathrm{a}=5 \mathrm{~cm} ; \mathrm{b}=3 \mathrm{~cm}$. 
Tabla 2 - Variaciones estructurales en las raíces aéreas cortas de Oenocarpus bataua Mart. E = exodermis; CE = corteza externa; $\mathrm{EI}=$ espacios intercelulares; $\mathrm{CPD}=$ células con paredes delgadas; $\mathrm{CDP}=$ células producto de divisiones periclinales entre cortezas externa e interna; $\mathrm{CI}=$ corteza interna; $\mathrm{PF}=$ paquetes de fibra; $\mathrm{E}=$ endodermis $\mathrm{C}=$ contorno; $\mathrm{NRL}=\mathrm{a}$ nivel de las raíces laterales; $\mathrm{M}=$ medula; $\mathrm{ETA}=$ elementos traqueales aislados; $\mathrm{P}=$ parénquima.

Table 2 - Structural variations in aerial short roots of Oenocarpus bataua Mart. E = exodermis; $\mathrm{CE}=$ outer cortex; EI = intercellular spaces; $\mathrm{CPD}=$ thin wall cells; $\mathrm{CDP}=$ cells from serial periclinal divisions between the outer and inner cortex; $\mathrm{CI}=$ inner cortex; $\mathrm{PF}=$ fiber bundles; $\mathrm{E}=$ endodermis; $\mathrm{C}=$ outline $\mathrm{NRL}=$ at the level of the lateral roots; $\mathrm{M}=$ medulla; $\mathrm{ETA}=$ isolated tracheary elements; $\mathrm{P}=$ parenchyma.

\begin{tabular}{|c|c|c|c|c|c|c|c|c|c|}
\hline & \multirow{2}{*}{ E y CE } & \multicolumn{2}{|r|}{ CE } & \multirow{2}{*}{ CDP } & \multirow{2}{*}{$\begin{array}{c}\text { CI } \\
\text { PF }\end{array}$} & \multicolumn{2}{|c|}{$\mathbf{E}$} & \multicolumn{2}{|c|}{$\mathbf{M}$} \\
\hline & & EI & CPD & & & C & NRL & ETA & $\mathbf{P}$ \\
\hline $\begin{array}{c}\text { Raíces } \\
\text { maduras } \\
1^{\mathrm{er}} \text { orden }\end{array}$ & $\begin{array}{c}\text { no se } \\
\text { distinguen } \\
\text { hacia el } \\
\text { ápice }\end{array}$ & no & $\begin{array}{c}\text { hacia zona } \\
\text { de raíces } \\
\text { laterales }\end{array}$ & si & presentes & circular & $\begin{array}{l}\text { predominan } \\
\text { células de } \\
\text { paredes } \\
\text { engrosadas }\end{array}$ & ausentes & abundante \\
\hline $\begin{array}{c}\text { Raíces } \\
\text { juveniles } 1^{\text {er }} \\
\text { orden }\end{array}$ & $\begin{array}{c}\text { se } \\
\text { distinguen }\end{array}$ & si & si & si & presentes & circular & $\begin{array}{l}\text { predominan } \\
\text { células de } \\
\text { paredes } \\
\text { delgadas }\end{array}$ & ausentes & abundante \\
\hline $\begin{array}{c}\text { Raíces } \\
\text { maduras } \\
\mathbf{1}^{\text {er }} \text { orden } \\
\text { mayor } \\
\text { diámetro }\end{array}$ & $\begin{array}{c}\text { no se } \\
\text { distinguen } \\
\text { hacia el } \\
\text { ápice }\end{array}$ & no & $\begin{array}{c}\text { hacia zona } \\
\text { de raíces } \\
\text { laterales }\end{array}$ & si & presentes & lobulado & $\begin{array}{l}\text { predominan } \\
\text { células de } \\
\text { paredes } \\
\text { engrosadas }\end{array}$ & presentes & abundante \\
\hline $\begin{array}{c}\text { Raíces } \\
\text { maduras } \\
2^{\text {do }} \text { orden }\end{array}$ & $\begin{array}{c}\text { no se } \\
\text { distinguen }\end{array}$ & no & no & no & ausentes & circular & $\begin{array}{l}\text { predominan } \\
\text { células de } \\
\text { paredes } \\
\text { engrosadas }\end{array}$ & ausentes & escaso \\
\hline
\end{tabular}

\section{Capas superficiales}

Rizodermis (epidermis) persistente, con cutícula, células heterodimensionales, cuadrangulares transversal y longitudinalmente, pared periclinal externa convexa, plana en las raíces de segundo orden, más engrosada que el resto de las paredes (Figs. 2b-f; 5a,b); más estrechas y pared externa aún más engrosada hacia el ápice. Exodermis (hipodermis) uniforme, con una a tres capas de células parenquimáticas esclerificadas alternando con células no esclerificadas, a veces ninguna de las células exodérmicas se esclerifica o, hacia el ápice, no pueden ser distinguidas de la corteza externa (Fig. 2b,c,e,f).

\section{Tejido cortical}

Corteza externa con número variable de capas de células parenquimáticas con paredes delgadas (en algunos casos éstas desaparecen en las adyacencias del ápice radical), seguidas por 3-6 capas de células pétreas siempre presentes, de paredes y lumen color pardo, cuadrangulares en sección tranversal (Fig. 2a-d), alargadas en sección longitudinal (Fig. 2f,g). En raíces juveniles, se observan las células pétreas en proceso de esclerificación (Fig. 2d). En raíces de segundo orden no se distingue la exodermis, encontrándose sólo las capas de células pétreas anteriormente mencionadas (Fig. 5b). Espacios intercelulares y grupos de células con paredes esclerificadas en la corteza externa de raíces juveniles de primer orden (Fig. 2d-e). Frecuentemente, entre la corteza externa e interna se encuentran 5-6 capas de células parenquimáticas de paredes muy delgadas provenientes de divisiones periclinales (Fig. 2h), obliteradas hacia el ápice y ausentes en raíces de segundo orden. Corteza interna extensa, de estructura constante desde la zona apical, con varias capas de células parenquimáticas, algunas con granos de almidón; paquetes de fibra de forma alargada, menos frecuente redondeada o fibras solitarias (Figs. 2a; 3a). Fibras de lumen amplio y células pétreas solitarias, poco frecuentes. Espacios intercelulares inconspicuos. Hacia el 
interior de esta región, cámaras aeríferas poco desarrolladas (Figs. 2a; 3a,e), luego 2-4 capas de células parenquimáticas ovaladas, en contacto con la endodermis; paquetes de fibra con células comparativamente menores y en menor cantidad que en las capas más externas. En las raíces de segundo orden la corteza interna con varias capas de esclerénquima, luego varios estratos de parénquima con pocas fibras solitarias (Fig.
$5 b, c)$ y cámaras aeríferas escasas. Endodermis uniestratificada, continua y circular (Figs. 3b,c,e-g; 4), lobulada en raíces de mayor diámetro (Fig. 3d), células con engrosamientos en "u" de las paredes radiales y tangencial interna (Figs. 3c,f; 4b,d,f,h), alternando con células de paredes no engrosadas hacia el ápice radical, en raíces juveniles, en la zona de formación de raíces laterales predominan las células de paredes delgadas en la endodermis
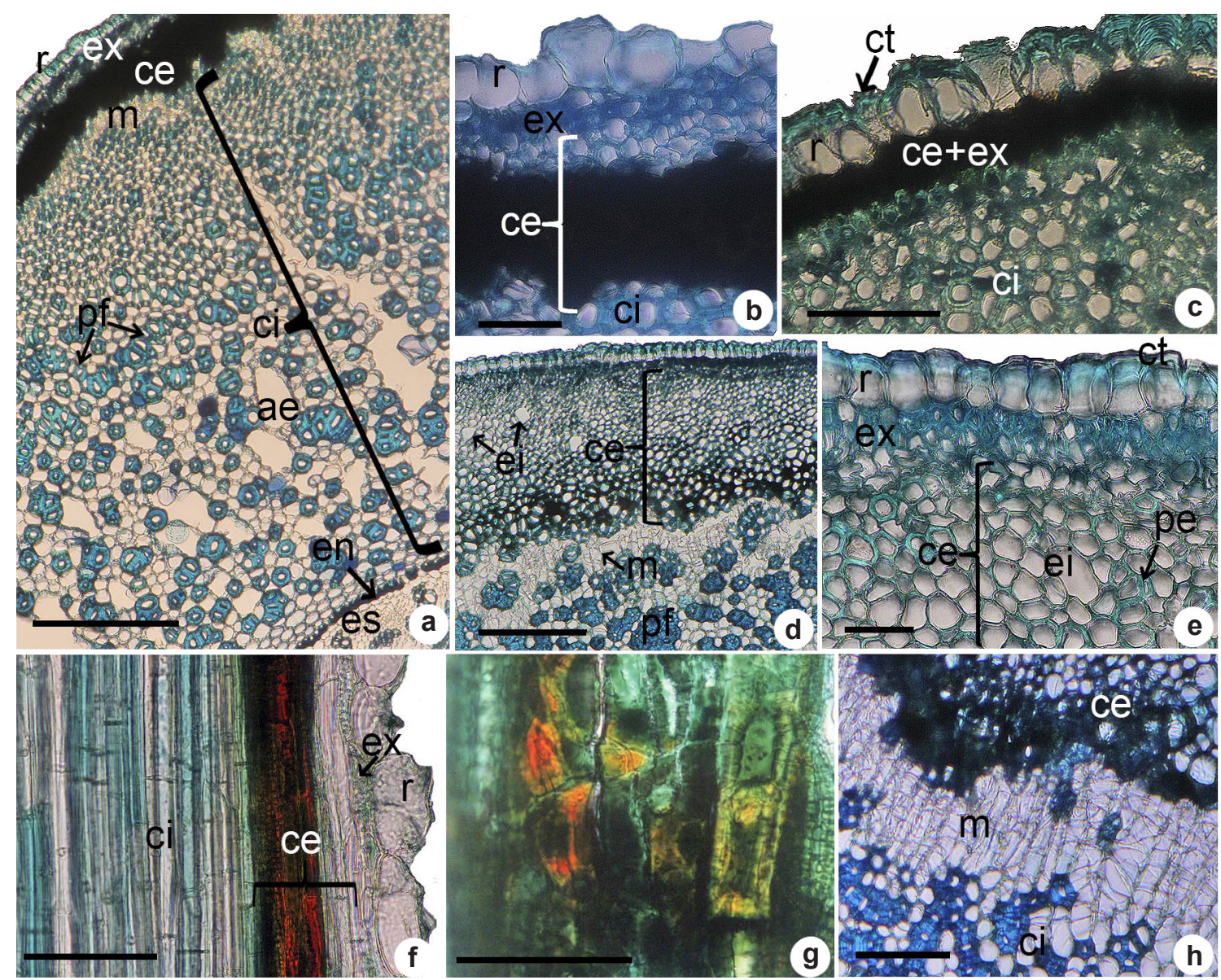

Figura 2 - Aspectos anatómicos de la porción externa de raíces aéreas de primer orden en Oenocarpus bataua Mart. - a. sección transversal de una raíz madura; b. detalle de la imagen anterior; c. tejidos externos de raíz madura en corte transversal cercano al ápice; d. región cortical de raíz juvenil en corte transversal, en zona de formación de raíces laterales; e. detalle de la imagen anterior; f. sección longitudinal de la rizodermis y la corteza en una raíz madura; g. detalle de las células pétreas de la corteza externa en sección longitudinal; h. capa de células producto de divisiones periclinales seriadas, entre la corteza externa e interna. (ae: cámara aerífera; ce: corteza externa; ci: corteza interna; ct: cutícula; ei: espacio intercelular; en: endodermis; es: estela; ex: exodermis; m: células provenientes de divisiones periclinales seriadas; pe: células parenquimáticas con paredes esclerificadas; pf: paquetes de fibra; r: rizodermis). Barras: a,d $=300 \mu \mathrm{m} ; \mathrm{b}, \mathrm{e}=50 \mu \mathrm{m} ; \mathrm{c}, \mathrm{f}, \mathrm{g}, \mathrm{h}=100 \mu \mathrm{m}$.

Figure 2 - Anatomical aspects of the outer portion of primary aerial roots in Oenocarpus bataua Mart. - a. cross section of a mature root; b. detail of the previous image; $\mathrm{c}$. external tissues of a mature root in cross section near the apex; $\mathrm{d}$. cortical region of juvenile root in a cross section of the lateral root development zone; e. detail of the previous image; f. longitudinal section of the rhizodermis and cortex in a mature root; g. detail of stone cells of the outer cortex in longitudinal section; $h$. layer of cells from serial periclinal divisions between the outer and inner cortex. (ae: air chamber; ce: outer cortex; ci: inner cortex; ct: cuticle; ei: intercellular space; en: endodermis; es: stele; ex: exodermis; m: cells from serial periclinal divisions; pe: parenchymatous cells with sclerified walls; pf: fiber bundles; r: rhizodermis). Bars: a,d $=300 \mu \mathrm{m} ; \mathrm{b}, \mathrm{e}=50 \mu \mathrm{m} ; \mathrm{c}, \mathrm{f}, \mathrm{g}, \mathrm{h}=100 \mu \mathrm{m}$. 


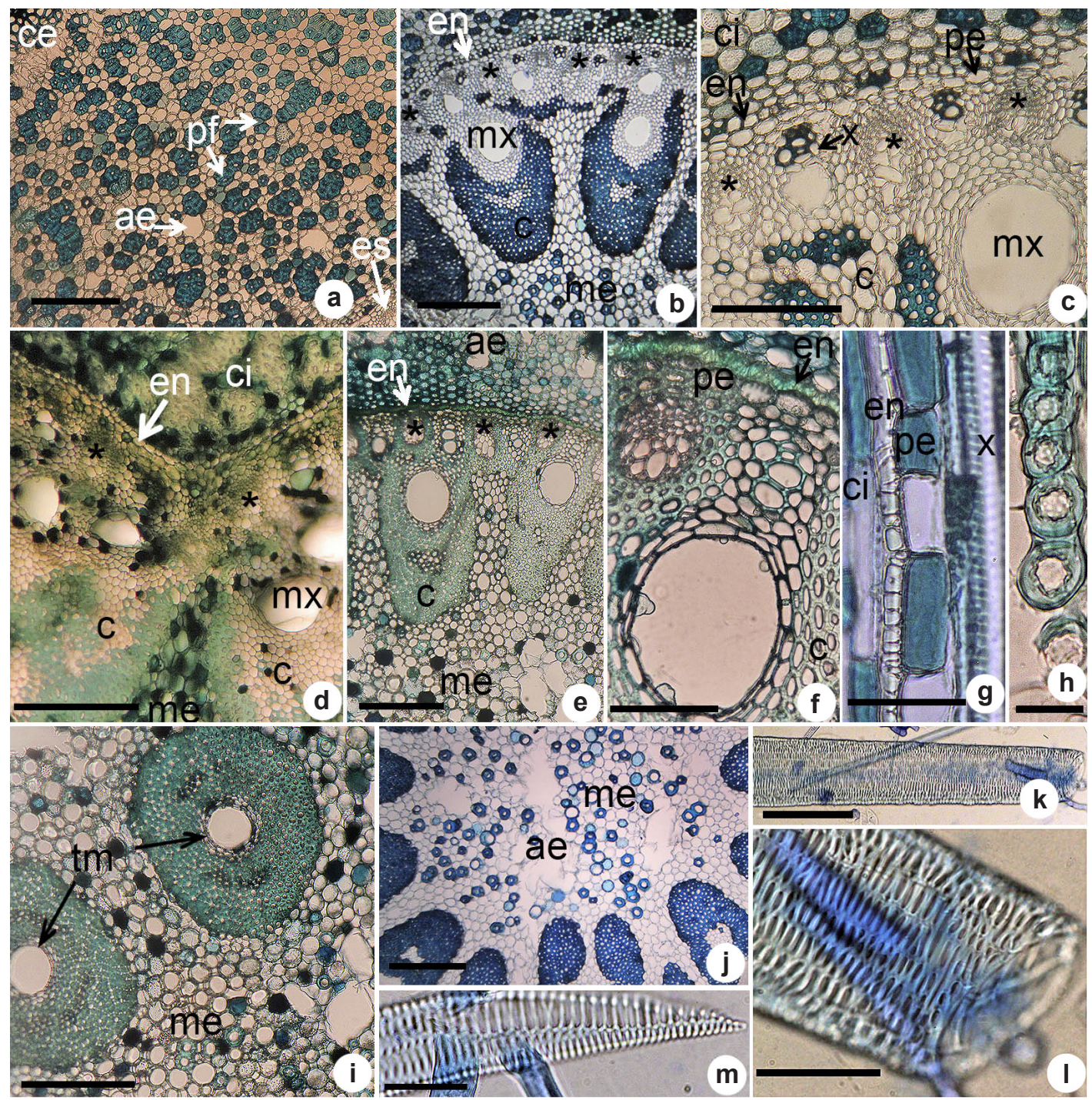

Figura 3 - Aspectos anatómicos de la porción interna de raíces aéreas de primer orden en Oenocarpus bataua Mart. - a. corte transversal de la corteza interna de una raíz juvenil en zona de raíces laterales; b. estela de la raíz mostrada en a; c. detalle de la imagen anterior; $d$. estela lobulada en raíz madura a $0,5 \mathrm{~cm}$ del ápice; e. estela en raíz madura a 0,5 cm del ápice; f. detalle de la imagen anterior. Nótese el elemento metaxilemático con inicio de tilosis; g. sección longitudinal de la endodermis y periciclo; $h$. fila longitudinal de stegmata con cuerpos de sílice, rodeando el tejido fundamental esclerificado que bordea al tejido vascular; i. detalle de médula en raíz madura a $3 \mathrm{~cm}$ del ápice, con elementos traqueales aislados, rodeados de tejido fundamental esclerificado; j. detalle de médula en raíz juvenil a nivel de las raíces laterales; $\mathrm{k}$. elemento traqueal metaxilemático; 1 . detalle de k, nótese paredes con engrosamientos escalariformes y placa con perforación simple; $m$. detalle de elemento traqueal protoxilemático, con engrosamiento de sus paredes y placa perforada escalariformes. (ae: cámaras aeríferas; c: tejido fundamental esclerificado que bordea al tejido vascular; ce: corteza externa; ci: corteza interna; en: endodermis; es: estela; me: médula; mx: metaxilema; pe: periciclo; pf: paquetes de fibra; tm: elementos traqueales medulares; $x$ : xilema; * floema). Barras: a,b,d,e,i,j=300 $\mu \mathrm{m} ; \mathrm{c}, \mathrm{f}, \mathrm{k}=100 \mu \mathrm{m} ; \mathrm{g}, 1, \mathrm{~m}, \mathrm{n}=50 \mu \mathrm{m} ; \mathrm{h}=25 \mu \mathrm{m}$. Figure 3 - Anatomical aspects of the inner portion of primary aerial roots in Oenocarpus bataua Mart. - a. cross section of the inner cortex of juvenile root in lateral root zone; $b$. stele of root shown in $\mathrm{a} ; \mathrm{c}$. detail of the previous image; $d$. lobulated stele in mature root at $0.5 \mathrm{~cm}$ from apex; e. stele in mature root at $0.5 \mathrm{~cm}$ from apex; f. detail of the previous image. Note the metaxylematic element with early tylosis; $\mathrm{g}$. longitudinal section of endodermis and pericycle; $h$. longitudinal row of stegmata with silica bodies surrounding sclerified fundamental tissue bordering the vascular tissue; i. detail of medulla in a mature root at $3 \mathrm{~cm}$ from the apex, with isolated tracheary elements surrounded by sclerified fundamental tissue; $\mathrm{j}$. detail of medulla in juvenile root at lateral roots level; $\mathrm{k}$. metaxylematic tracheary element; 1 . detail of $\mathrm{k}$, note scalariform wall thickening and simple perforation plate; $\mathrm{m}$. detail of a protoxylematic tracheary element, with scalariform wall thickening and perforation plate. (ae: air chamber; c: fundamental tissue bordering the vascular tissue; ce: outer cortex; ci: inner cortex; en: endodermis; es: stele; me: medulla; mx: metaxylem; pe: pericycle; pf: fiber bundles; tm: medullary tracheary

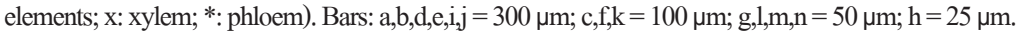


(Fig. 3c). Estos engrosamientos se hacen más evidentes y las células de paredes delgadas se hacen escasas a partir de $2-3 \mathrm{~cm}$ del ápice o en la zona de formación de raíces laterales en raíces maduras (Figs. 3f; 4b,d,f,h). Raíces de segundo orden con células endodérmicas en su mayoría de paredes muy engrosadas en toda su longitud (Fig. 5d-f).

\section{Estela}

Poliarca, con unos 17 polos protoxilemáticos en raíces de menor diámetro y de segundo orden y 20-24 en las de mayor diámetro. Periciclo con 1-2 capas de células parenquimáticas (Figs. $3 \mathrm{c}, \mathrm{f}, \mathrm{g} ; 4 \mathrm{~b}, \mathrm{~d}, \mathrm{f}, \mathrm{h})$, formando raíces laterales; en raíces de segundo orden, con células esclerificadas (Fig. 5d-f). Tejido vascular rodeado por tejido fundamental que se va esclerificando de manera centrífuga desde el ápice (Figs. 3b,c; 4a-d) hacia la zona de formación de raíces laterales (Figs. 3e,f; 4e-h), está bordeado por filas longitudinales discontinuas de stegmata con cuerpos de sílice esféricos, espinulosos en su límite con la médula (Fig. 3h). Raíces de segundo orden con tejido que bordea al conductor esclerificado, con células de lumen reducido (Fig. 5d-f). Elementos traqueales con engrosamientos escalariformes (Fig. $3 \mathrm{k}-\mathrm{m}$ ). Elementos traqueales del metaxilema con paredes delgadas y placa perforada simple (Fig. $3 \mathrm{k}, 1)$, los del protoxilema con placa perforada escalariforme (Fig. 3m). Médula parenquimática (Fig. 3e,i,j), con amiloplastos, a veces cámaras aeríferas (Fig. 3j). Células esclerenquimáticas dispersas, solitarias o en grupos pequeños. Debido a la disposición del tejido fundamental esclerificado bordeando al tejido vascular, la médula se observa acanalada (Figs. 3e; 4a,c,e,g). En raíces de mayor diámetro se encontraron elementos traqueales medulares rodeados por tejido fundamental esclerificado (Fig. 3i). En raíces de segundo orden, el tejido parenquimático medular está reducido (Fig. 5d-f).
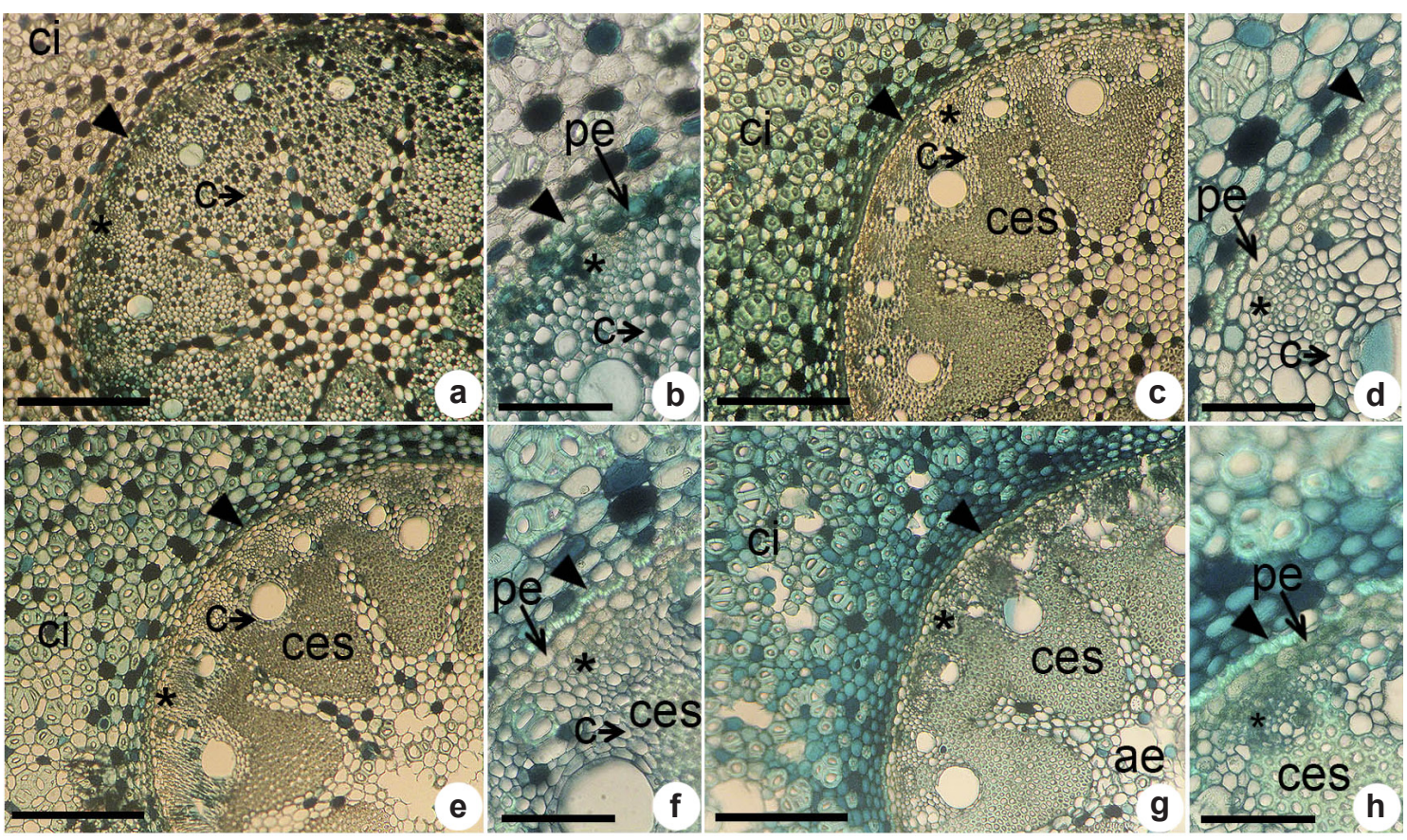

Figura 4 - Sección transversal seriada de raíz aérea madura de primer orden de Oenocarpus bataua Mart. a distintas distancias del ápice. Detalles de las zonas cortical interna y parte externa de la estela. - a-b. a 0,1cm del ápice; c-d. a 1 cm del ápice; e-f. a 2,5 cm del ápice; g-h. a 3,5 cm del ápice. (ae: cámara aerífera; c: tejido fundamental no esclerificado bordeando al tejido vascular; ces: tejido fundamental esclerificado bordeando al tejido vascular; ci: corteza interna; pe: periciclo; cabeza de flecha: endodermis; *: floema). Barras: a,c,e,g $=300 \mu \mathrm{m} ; \mathrm{b}, \mathrm{d}, \mathrm{f}, \mathrm{h}=100 \mu \mathrm{m}$.

Figure 4 - Serial cross sections of mature primary aerial root of Oenocarpus bataua Mart. at different levels from apex. Details of inner cortex and outer part of the stele. - a-b. at $0.1 \mathrm{~cm}$ from apex; c-d. at $1 \mathrm{~cm}$ from apex; e-f. at 2,5 cm from apex; g-h. at 3,5 cm from apex. (ae: air chamber; c: not sclerified fundamental tissue bordering the vascular tissue; ces: sclerified fundamental tissue bordering the vascular tissue; ci: inner cortex; pe: pericyle; arrow head: endodermis; *: phloem). Bars: a,c,e,g $=300 \mu \mathrm{m} ; \mathrm{b}, \mathrm{d}, \mathrm{f}, \mathrm{h}=100 \mu \mathrm{m}$. 


\section{Discusión}

Las raíces aéreas cortas de primer y segundo orden en $O$. bataua presentan una anatomía similar a lo reportado por Seubert (1998a) en raíces subterráneas del género Oenocarpus. A diferencia del tallo, las raíces mantienen una estructura primaria con un plan básico independiente del lugar donde se originen (Rudall 2007); pudiendo existir variaciones sobre todo de tipo cuantitativo, como ha sido señalado en eudicotiledóneas (Greig \& Mauseth 1991). No se observó tejido meristemático apical, por lo que estas raíces no son capaces de continuar su crecimiento, en su lugar tienen actividad del periciclo para el desarrollo de raíces laterales.

La exodermis es de estructura variable entre los individuos, en el número de capas y engrosamiento de las paredes. Seubert (1998a) mencionó la variación en el número de capas de este tejido entre Oenocarpus y Jessenia, este último género, incluido en Oenocarpus (Henderson 1995, 1999). Seubert (1998b) describió dos zonas en la corteza externa en raíces de Euterpeae; en este trabajo se encontró un arreglo similar, pero de

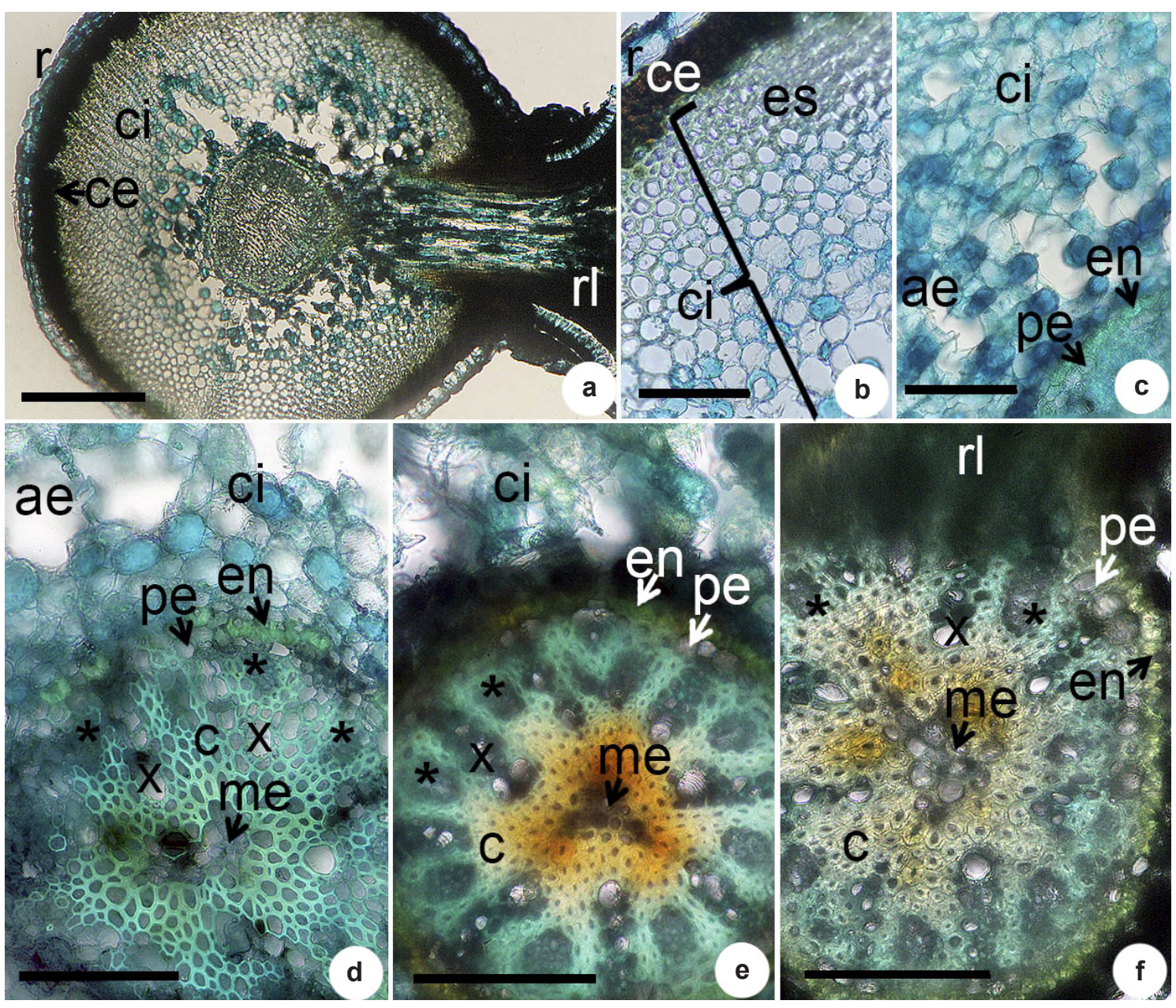

Figura 5 - Sección transversal de raíces aéreas de segundo orden de Oenocarpus bataua Mart. - a. vista general con raíz terciaria emergente; b. detalle de las capas superficiales y corticales; c. detalle de la corteza interna; $d$. estela a $0,1 \mathrm{~cm}$ del ápice; e. estela a 1 $\mathrm{cm}$ del ápice; f. estela a 1,5 cm del ápice. (ae: aerénquima; ce: corteza externa; ces: tejido fundamental esclerificado que bordea al tejido vascular; ci: corteza interna; en: endodermis; es: tejido parenquimático esclerificado en la parte externa de la corteza interna; pe: periciclo; me: médula; r: rizodermis; rl: raíz lateral terciaria; x: xilema; *: floema). Barras: a = $300 \mu \mathrm{m}$; b-f $=100 \mu \mathrm{m}$.

Figure 5 - Cross section of secondary aerial roots of Oenocarpus bataua Mart. - a. general view with an emerging tertiary root; b. detail of superficial and cortical layers; c. detail of inner cortex; $d$. stele at $0,1 \mathrm{~cm}$ from apex; e. stele at $1 \mathrm{~cm}$ from apex; f. stele at 1,5 cm from apex. (ae: air chamber; ce: outer cortex; ces: fundamental tissue bordering the vascular tissue; ci: inner cortex; en: endodermis; es: sclerified parenchyma in the outer part of the inner cortex; pe: pericycle; me: medulla; r: rhizodermis; rl: lateral tertiary root; x: xylem; *: phloem). Bars: a $=300 \mu \mathrm{m}$; b-f $=100 \mu \mathrm{m}$. 
manera variable; en la primera zona, las células de paredes delgadas pueden estar ausentes, a veces únicamente faltando hacia el ápice y en la segunda zona, las células son siempre fuertemente esclerificadas (células pétreas), de color pardo tanto en paredes como en lumen celular, confiriéndole aspecto leñoso a las raíces. Dichas células pueden estar en contacto con la exodermis, como indicaron Tomlinson et al. (2011).

El tejido con células sin diferenciación, provenientes de divisiones periclinales seriadas, encontrado entre la corteza externa e interna no ha sido definido por los autores consultados. En la periferia de la corteza interna de raíces viejas de palmas, se pueden encontrar células con paredes lignosuberizadas, producto de repetidas divisiones periclinales, que son capas protectoras típicas en órganos de monocotíledóneas (Tomlinson 1961; Tomlinson et al. 2011); sin embargo, no se observaron paredes engrosadas con estas características. Seubert (1996, 1998a) ubica en la capa más externa de la corteza interna, la formación de un tejido parecido al felema. En monocotiledóneas, este tipo de tejido se forma en respuesta a un daño, dividiéndose las células en una o más capas por debajo de la zona dañada, las células formadas generalmente no retienen la capacidad meristemática, con excepciones donde las adyacentes a las divididas adquieren actividad de este tipo (Priestley \& Swingle 1929). Es posible que al tratarse de raíces aéreas y no existir erosión de tejidos superficiales, las células formadas no se suberificaron.

La conformación de la corteza interna es homogénea, poco variable entre los individuos y difícilmente separable en las tres regiones indicadas por Tomlinson et al. (2011) y Seubert (1998a), debido al poco desarrollo del aerénquima y a que el contorno de los paquetes de fibra se mantiene similar en toda la corteza. Las características encontradas en los paquetes de fibra coinciden en algunos aspectos con el tipo Kentia señalado por Tomlinson (1961) y Tomlinson et al. (2011) para las Arecoideae, ya que hacia la periferia hay poca variación tanto en la cantidad de fibras de los paquetes como en el tamaño del lumen celular y no se observó una transición clara desde fibras solitarias hasta agrupadas.

Como es típico en raíces aéreas, se encontró un aerénquima poco desarrollado en la corteza. En palmas, este aerénquima puede tener origen tanto esquizógeno como lisígeno (Seubert 1998a) y un aerénquima más desarrollado se observa en palmas que habitan zonas muy húmedas (Tomlinson et al. 2011), en este caso su origen es lisígeno (Seubert 1998a).

La endodermis continua, coincide con la descrita en Arecoideae por Seubert (1998a); sin embargo, en las raíces de mayor diámetro se notaron fuertes lobulaciones en la misma. Tomlinson et al. (2011) señalan que en raíces de Arecoideae se encuentra una endodermis lobulada continua, a medida que incrementa el diámetro, se hace discontinua al separarse los lóbulos. Las características de la estela son similares a las del tipo iii mencionado por Tomlinson (1961), al ser cilíndrica, con médula acanalada y elementos de vasos medulares aislados, rodeados de tejido fundamental esclerificado. Esta última característica puede o no estar presente, y pareciera depender de una ligera variación en el grosor de la raíz. Es importante destacar la presencia stegmata rodeando al tejido fundamental esclerificado que bordea al tejido vascular, que no ha sido reportado para la tribu Euterpeae, sino para la Areceae (Tomlinson et al. 2011). Este carácter podría apoyar la afinidad entre las dos tribus, que a pesar de ser grupos molecularmente distintos, ha sido difícil separarlos desde el punto de vista morfológico (Baker et al. 2011).

La esclerificación centrífuga del tejido fundamental que bordea al tejido vascular mostrada en este trabajo, podría ser comparable con una característica que fue reportada para los haces fibrovasculares en el tallo de palmas dentro de Arecoideae, Ceroxyloideae, Calamoideae erectas, y en una sola tribu de Coryphoideae, donde existe una diferenciación centrífuga de las fibras que componen la capa fibrosa dorsal de estos haces, condición que parece ser única para las palmas (Thomas \& De Franceschi 2013).

En síntesis, la estructura de la corteza externa, la presencia de vasos aislados medulares y las lobulaciones de la endodermis, son rasgos que varían entre y en un mismo individuo, por lo que no parecen ser caracteres útiles taxonómicamente y aparentan estar relacionados a pequeñas diferencias en el diámetro radical. A distintos niveles desde el ápice, las principales variaciones tienen que ver con el engrosamiento de paredes celulares de los tejidos, manteniéndose más o menos constante a partir de la zona de desarrollo de raíces laterales. Los paquetes de fibra de contornos irregulares presentes en la corteza interna, son un carácter constante en raíces de primer orden y sus características no coinciden claramente con las 
descritas por los autores en raíces subterráneas. Las raíces de segundo orden tienen estructura más simple y más constante a diferentes distancias del ápice, que las de primer orden.

\section{Agradecimientos}

A Fani Tinitana y Nixon Cumbicus, por la recolección del material. Al Proyecto Prometeo de la Secretaría de Educación Superior, Ciencia, Tecnología e Innovación de la República del Ecuador, y a la UTPL (PROY_CCNN_851), por el financiamiento.

\section{Referencias}

Baker, W.J.; Norup, M.V.; Clarkson, J.J.; Thomas, L.P.; Couvreur, T.L.P.; Dowe, J.L.; Lewis, C.E.; Pintaud, J.C.; Savolainen, V.; Wilmot, T. \& Chase, M.W. 2011. Phylogenetic relationships among arecoid palms (Arecaceae: Arecoideae). Annals of Botany 108: $1417-1432$

Biondi, E. \& Filigheddu, R.S. 1990. A palm fossil closely related to Chamaerops humilis L. from the Lower Miocene of Sardinia. Giornale Botanico Italiano 124: 711-724.

Borchsenius, F. \& Moraes, M. 2006. Diversidad y usos de palmeras andinas (Arecaceae). In: Moraes, M.; Øllgaard, B.; Bochsenius, F. \& Balslev, H. (eds.). Botánica económica de los Andes Centrales. Universidad Mayor de San Andrés, La Paz. Pp. 412-433.

Dransfield, J.; Uhl, N.W.; Asmussen, C.B.; Baker, W.J.; Harley, M.M. \& Lewis, C.E. 2008. Genera palmarum: The evolution and classification of palms. Kew Publishing, Royal Botanical Gardens, Kew. 732p.

Dutta, D.; Ambwani, K. \& Estrada-Ruiz, E. 2011. Late Cretaceous palm stem Palmoxylon lametaei sp. nov. from Bhisi Village, Maharashtra, India. Revista Mexicana de Ciencias Geológicas 28: 1-9.

Franklin, L. 1945. Preparation of thin sections of synthetic resin and wood. Resin composites, and a new macerating method for wood. Nature 155: 51.

Greig, N. \& Mauseth, J.D. 1991. Structure and function of dimorphic prop roots in Piper auritum. Bulletin of the Torrey Botanical Club 118: 176-183.

Heimsch, C. \& Seago, J.L. 2008. Organization of the root apical meristem in Angiosperms. American Journal of Botany 95: 1-21.

Henderson, A. 1995. The Palms of the Amazon. Oxford University Press, New York. 388p.

Henderson A.; Galeano, G. \& Bernal, R. 1995. Field guide to the palms of the Americas. Princeton University Press, New Jersey. 352p.
Henderson, A. 1999. A phylogenetic analysis of Euterpeinae (Palmae) based on morphology and anatomy. Brittonia 51: 106-113.

Hodel, D.R.; Pittenger, D.R. \& Downer, A.J. 2005. Palm root growth and implications for transplanting. Journal of Arboriculture 3: 171-181.

Hodel, D.R. 2009. Biology of palms and implications for management in the landscape. Horttechnology 19: 676-681.

Johansen, D.A. 1940. Plant Microtechnique. Mc Graw Hill, New York. 523p.

Lewis, C. 2002. A phylogenetic analysis of the palm subtribe Oncospermatinae (Arecaceae) based on morphological characters. Brittonia 54: 78-91.

Mahabale, T. \& Udwadia, N. 1959. Studies on palms: Part IV-Anatomy of palm roots. Proceedings of the National Institute of Sciences of India, B, Biological Sciences 26: 73-104.

Pittenger, D.R.; Hodel, D.R. \& Downer, A.J. 2005. Transplanting specimen palms: a review of common practices and research-based information. Horttechnology 15: 128-132.

Priestley, J.H. \& Swingle, C.F. 1929. Vegetative propagation from the standpoint of plant anatomy. United States Department of Agriculture Technical Bulletin 151: $1-98$.

Rudall, P.J. 2007. Anatomy of flowering plants: an introduction to structure and development. $3^{\text {rd }}$. ed. Cambridge University Press, Cambridge. 137p.

Seago, J.L. \& Fernando, D.D. 2013. Anatomical aspects of angiosperm root evolution. Annals of Botany 112: 223-238.

Seubert, E. 1996. Root anatomy of palms III. Ceroxyloideae, Nypoideae, Phytelephantoideae. Feddes Repertorium 107: 597-619.

Seubert, E. 1998a. Root anatomy of palms IV. Arecoideae, part I, General remarks and descriptions on the roots. Feddes Repertorium 109: 89-127.

Seubert, E. 1998b. Root anatomy of palms IV. Arecoideae, part 2, Systematic implications. Feddes Repertorium 109: 231-247.

Thomas, R. \& De Franceschi, D. 2013. Palm stem anatomy and computer-aided identification: the Coryphoideae (Arecaceae). American Journal of Botany 100: 289313.

Tidwell, W.D.; Medlyn, D.A. \& Thayni, G.F. 1972. Fossil palm materials from the tertiary dipping vat formation of central Utah. The Great Basin Naturalist 32: 1-15.

Tomlinson, P.B. 1961. Palmae. In: Metcalfe, C.R. (ed.). Anatomy of the Monocotyledons II. Clarendon Press, Oxford. Pp. 1-453.

Tomlinson, P.B; Horn, J.W. \& Fisher, J.B. 2011. The anatomy of palms. Clarendon Press, Oxford. 276p. 